\title{
Reutilização de embalagens de papelão: estudo de caso em distribuição de suprimentos
}

\section{Reuse of paperboard packaging: a case study on distribution of supplies}

\author{
Fabiano de Lima Nunes ${ }^{1}$ \\ Virgínia Silva Dias ${ }^{1}$ \\ Miguel Afonso Sellitto ${ }^{1}$
}

\begin{abstract}
Resumo: Este artigo descreve um estudo de caso sobre reutilização das embalagens de papelão recebidas de fornecedores e reaproveitadas para o empacotamento de produtos a serem distribuídos e entregues a clientes em uma empresa de distribuição de suprimentos. A questão de pesquisa é: como a reutilização de embalagens de papelão impacta na operação de uma empresa de distribuição de suprimentos corporativos com abrangência nacional. Inicialmente, apresenta-se uma revisão teórica a respeito de embalagens, impacto ambiental e armazenagem. A seguir, descreve-se o caso, de acordo com as informações colhidas pelos pesquisadores junto à empresa estudada. Descrevem-se os fatos, investigam-se as causas que os originaram e compara-se o processo anterior ao atual, que contempla a reutilização de embalagens. Houve ganhos econômicos e ambientais: redução de $86 \%$ na compra de embalagens novas de papelão, e redução de $87,3 \%$ na pegada de carbono gerada pela operação.
\end{abstract}

Palavras-chave: Distribuição; Logística; Gestão ambiental; Gestão da cadeia de suprimentos; Gestão de resíduos.

\begin{abstract}
This article describes a case study on the reuse of cardboard packages received from suppliers and reused for the packaging of products to be distributed and delivered to customers in a supply distribution company. The research question is: How does the reuse of cardboard packaging impact the operation of a corporate supply and distribution company with national reach? Initially, the article presents a theoretical review on packaging, environmental impact, and storage. After that, the case is described according to the information collected by researchers at the studied company. The facts and their causes are described and investigated. A comparison, which includes the introduction of the reuse of packaging, is made between the current and former processes. There have been economic and environmental gains: reduction of $86 \%$ on the purchase of new cardboard packaging, and reduction of $87.3 \%$ on carbon footprint generated by the operation.
\end{abstract}

Keywords: Distribution; Logistics; Environmental management; Supply chain management; Waste management.

\section{Introdução}

Dada a crescente demanda da sociedade por operações industriais ambientalmente corretas, as empresas deste setor têm incorporado às suas estratégias de produção ações de prevenção e de desenvolvimento ambiental (Yang et al., 2010). Hoje, exige-se das empresas mais do que o mero cumprimento das regulamentações ambientais, mas também posturas proativas em relação ao ambiente e à sociedade (Rao, 2007; Sharfman et al., 1997). Além dos objetivos econômicos, a gestão das cadeias de suprimentos deve impor objetivos sociais e ambientais à empresa focal e às demais empresas da cadeia (Ciliberti et al., 2008), o chamado tripé da sustentabilidade (triple bottom line) (Azzi et al., 2012).
Um dos aspectos que permeiam esse debate é a aparente dicotomia entre objetivos ambientais e econômicos (Yang et al., 2011). Qi \& Chang (2013) sugerem que os sistemas produtivos adotem soluções que integrem tanto objetivos econômicos como ambientais. Apesar da aparente divergência, empresas têm reconhecido que ações de desenvolvimento ambiental podem aumentar suas competitividades, mesmo que em algumas vezes ainda não haja clareza absoluta sobre os detalhes das práticas de gestão ambiental (Montabon et al., 2007). Modelos de processos podem ser desenvolvidos de forma a minimizar a geração de resíduos e reduzir o consumo de recursos, aumentando a competitividade global

\footnotetext{
${ }^{1}$ Programa de Pós-Graduação em Engenharia de Produção e Sistemas, Universidade do Vale do Rio dos Sinos - Unisinos, Av. Unisinos, 950, CEP 93022-000, São Leopoldo, RS, Brasil, e-mail: fabiano@forwin.com.br; virginiasd@gmail.com; sellitto@unisinos.br
} 
da empresa por redução de custos e por melhoria de imagem devido à minimização dos impactos ambientais (Silva et al., 2013).

Práticas de gestão ambiental têm exigido que as organizações façam investimentos em pessoas, em infraestrutura e também em processos para a sua implementação (Jabbour \& Santos, 2008). Por exemplo, a implementação de reciclagens e práticas de reutilização de produtos e componentes requer infraestruturas e investimentos adicionais para a recuperação de valores eventualmente ainda remanescentes (Kocabasoglu et al., 2007).

A gestão ambiental tem sido foco de pesquisas acadêmicas e de estudos empresariais ao longo dos últimos anos. Embora em muitos estudos o viés preponderante de análise seja o ganho econômico, também é possível identificar ganho em aspectos ambiental e social. Muitas empresas têm uma estratégia ou plano operacional para tratar a sustentabilidade em suas cadeias de suprimentos, com foco nos pilares econômico e social, não só ambiental (Morali \& Searcy, 2013).

Uma das indústrias que pode gerar impactos ambientais significativos em suas operações é a do papel e celulose. Um dos produtos desta indústria é o papelão ondulado, de alto custo, usado como embalagem para o transporte de produtos. Diante deste contexto, empresas de varejo e de distribuição estão sob crescente pressão para reduzir o uso de embalagens de papelão ondulado (Nordstrand, 2004; Gustafsson et al., 2005). Ou seja, a embalagem surge como elemento-chave em estratégias que combinem objetivos de eficiência econômica e de desenvolvimento ambiental (García-Arca et al., 2014).

Estudos relacionados à reutilização de embalagens enfocaram a redução de utilização de embalagens na fonte (Van Sluisveld \& Worrell, 2013), o impacto ambiental das embalagens em seu destino (Verghese \& Lewis, 2007), o impacto ambiental na comparação entre embalagens de papelão e embalagens retornáveis em plástico (Levi et al., 2011), o uso de embalagens retornáveis nas operações logísticas de transporte internacional (Adlmaier \& Sellitto, 2007) e a comparação entre embalagens retornáveis e descartáveis (Silva et al., 2013). Também foram abordados os temas das embalagens de papelão (Chen et al., 2011; Abbès \& Guo, 2010; Harrysson \& Ristinmaa, 2008) e seus custos na logística (Arvidsson \& Carlen, 2012; Azzi et al., 2012; Verghese \& Lewis, 2007), o armazenamento de materiais (Pohl et al., 2011; Aly, 2010; Koster et al., 2007; Gu et al., 2007), a separação e racionalização na coleta dos pedidos (picking) (Bukchin et al., 2012; Gu et al., 2010; Aly, 2010; Van Nieuwenhuyse \& Koster, 2009; Parikh \& Meller, 2008; Koster et al., 2007; Lin \& Lu, 1999), a pegada de carbono (Amorim, 2013; Chakraborty \& Roy, 2013; Eriksson et al., 2010) e a compensação ambiental por operações industriais poluidoras (Kageyama et al., 2008; Ramseur, 2008).

O objetivo deste artigo é descrever o processo de reutilização de embalagens de papelão e os resultados ambientais e econômicos desta prática em uma empresa de distribuição de materiais corporativos. A questão de pesquisa é: Como a reutilização de embalagens de papelão pode impactar a operação de uma empresa de distribuição de suprimentos corporativos? Os objetivos específicos da pesquisa foram: Analisar o impacto junto aos processos operacionais na função armazenagem na empresa; analisar o impacto nos custos de compra de embalagens novas; e analisar o impacto ambiental promovido pela reutilização de embalagens de papelão. $\mathrm{O}$ método de pesquisa foi o estudo de caso.

O restante do artigo está organizado em: revisão, estudo de caso, resultados e discussão, e conclusões.

\section{Embalagens}

Além de proteger produtos em transporte, novos requisitos foram acrescidos ao projeto de embalagem (Williams et al., 2008). Alguns destes requisitos têm o objetivo de melhorar a capacidade de diferenciação do produto (função comercial). Outros, têm como objetivo melhorar a eficiência produtiva do produto em níveis de serviços logísticos (função logística) (García-Arca et al., 2014). Autores como Bramklev (2009) e Azzi et al. (2012) identificaram na embalagem uma terceira função: a ambiental. Segundo os autores, a embalagem, se reaproveitada ou recondicionada, pode ter um papel significativo em estratégias de produção que considerem aspectos ambientais.

Embalagens têm melhorado soluções logísticas para o problema da distribuição. Projetos de embalagens têm sido elementos fundamentais para o desenvolvimento de novos sistemas de distribuição, tais como o sistema Tetra Pak, com dimensões regulares, e o IKEA, com suas embalagens planas. Outras soluções inovadoras também têm sido desenvolvidas, adaptando cargas à paletização e conteinerização, principalmente para cargas destinadas aos modais ferroviário e aquaviário (Rundh, 2009). Embalagens participam da maioria das atividades logísticas, impactando diretamente custos e desempenho ambiental (Verghese \& Lewis, 2007). Mesmo embalagens reutilizáveis possuem custos de gestão de retorno que podem ser significativos (Arvidsson \& Carlen, 2012).

A União Europeia (UE) reconheceu a necessidade de impor à indústria uma legislação correspondente, com o intuito de incentivar as empresas a conduzirem ações de desenvolvimento ambiental. Dentre outras legislações, foi emitida uma normativa relativa a embalagens, cujo objetivo é estimular a redução de resíduos e a quantidade de materiais a reciclar. A normativa promove também a recuperação de energia, reutilização e reciclagem de embalagens, 
por meios de procedimentos de logística reversa (Rundh, 2009).

Gustafsson et al. (2005) classificam embalagens em primárias, secundárias e terciárias. Embalagens primárias acondicionam produtos entregues ao consumidor final nos pontos de venda (por exemplo, garrafas). Embalagens secundárias, ou pacotes para transportes, são projetados para conter várias embalagens primárias (por exemplo, engradados). A embalagem secundária pode acompanhar o consumidor final ou ser usada por varejistas para expor produtos nas prateleiras. Embalagens terciárias são usadas para transporte e armazenagem (por exemplo, palete ou container), agrupando embalagens primárias e secundárias.

Tanto a demanda por embalagens como seu potencial impacto ambiental têm crescido. Para controlar este impacto, é importante inserir a embalagem também na perspectiva ambiental, não apenas econômica: é importante que possam ser recicladas ou reutilizadas mais facilmente, minimizando o impacto ambiental (Pelegrini, 2005). Para Silva et al. (2013), ganhos econômicos e ambientais significativos são possíveis pela redução no consumo de material de embalagens e na geração de resíduos de embalagens. Além destes, a reutilização de embalagens pode trazer benefícios logísticos: a operação logística fica menos complexa e menos sujeita a variabilidades presentes nos processos produtivos (Adlmaier \& Sellitto, 2007).

Para este artigo interessam mais as embalagens de papelão.

Embalagens de papelão ondulado têm sido largamente utilizadas, por apresentarem vantagens em relação a outros materiais: peso leve, baixo custo, boa selagem, bom amortecimento, fácil montagem e desmontagem, e simples recuperação e tratamento de resíduos (Chen et al., 2011). O material conhecido como cartão ondulado é laminado em camadas: os forros (camadas externas planas) e o corrugado (núcleo ondulado) (Abbès \& Guo, 2010). Segundo a Associação Brasileira de Papelão Ondulado (ABPO, 2014), o papelão ondulado é uma estrutura formada por um ou mais elementos ondulados, chamados de miolos, fixados por adesivo aplicado ao topo das ondas a um ou mais elementos fixos, chamados de capa. $\mathrm{O}$ número de miolos e capas seguem classificação regulamentada pela norma NBR 5985 (ABNT, 2008). O peso suportado pela caixa de papelão ondulado está associado à largura e à profundidade da marca de linha de prensagem de papelão. Largura e profundidade excessiva do vinco levarão à ruptura do papel interior (Harrysson \& Ristinmaa, 2008).

\subsection{Relação com a função armazenagem}

A armazenagem desempenha papel vital nas cadeias de suprimento industriais (Baker \& Canessa, 2009). Sua função é preservar e destinar os materiais com rapidez e segurança (Veludo, 2004). As funções básicas da armazenagem são: (i) recebimento; (ii) armazenamento; (iii) separação de pedidos (picking); e (iv) expedição (Gong \& Koster, 2011; Rouwenhorst et al., 2000).

A armazenagem inicia pela descarga nas docas de recebimento. Em seguida, atualiza-se o registro de estoque, faz-se a inspeção de qualidade e fazem-se eventuais reembalamentos, nos casos de unitização ou fracionamento da carga em paletes ou outros tipos de embalagens (Gu et al., 2007).

Armazenamento é o processo de atribuição de locais para os itens em um armazém ( $\mathrm{Gu}$ et al., 2007). Três decisões são fundamentais em armazenamento: a quantidade a ser recebida de cada SKU (Stock Keeping Unit - Unidade de Manutenção de Estoque); a frequência de recebimento; e o local de armazenamento (Aly, 2010). São cinco as lógicas usadas para o armazenamento: aleatório; no local disponível mais próximo, dedicado (local fixo), por volume total de negócios e baseado em classes de produtos (Koster et al., 2007). O armazenamento aleatório aproveita melhor o espaço; o mais próximo otimiza o deslocamento de entrada; o dedicado otimiza o gerenciamento da informação; o por volume de negócio otimiza o deslocamento de coleta; o por classe de produto garante a segurança, por evitar acidentes e contaminações (Pohl et al., 2011).

A separação de pedidos (picking) é o processo de retirada de itens dos locais de armazenamento para atender aos pedidos dos clientes (Bukchin et al., 2012). É objetivo da separação maximizar o nível de serviço, sujeito às restrições de mão de obra, equipamentos e capital e à variabilidade do tempo de entrega requerido. Seu desempenho é aferido por índices de integridade e acurácia do pedido (Koster et al., 2007). As estratégias de separação são classificadas em: discreta, em lotes, por zona e em ondas, podendo ocorrer combinações. Na discreta, um separador é responsável por pegar todos os itens. Na por lote, o separador coleta vários pedidos e os agrupa em lote. Na por zona, a cada separador é atribuída uma região específica da área de armazenamento. Na por ondas, a separação de pedidos e a expedição são sincronizadas: os pedidos são separados e embarcados de acordo com uma prévia programação de coleta (Parikh \& Meller, 2008; Van Nieuwenhuyse \& Koster, 2009; Gu et al., 2010). A escolha da estratégia de separação depende principalmente do número de itens separados e da quantidade de unidades por item (Lin \& Lu, 1999).

Acúmulo de encomendas separadas por pedidos de clientes, também chamado de consolidação, é uma atividade necessária se as ordens foram escolhidas em lotes. Este acumulo e processos de triagem, geralmente podem aplicar equipamentos mecânicos, como transportadores e separadores (Gong \& Koster, 2011). A consolidação refere-se 
ao agrupamento de produtos destinados ao mesmo cliente (Rouwenhorst et al., 2000). Este processo é realizado após a separação de pedidos (picking) e estes SKUs serão transportados para a consolidação, na qual ocorrerá o agrupamento dos itens destinados a um mesmo cliente. Depois deste agrupamento, os pedidos seguirão para o processo de conferência e/ou transporte (Shiau \& Lee, 2010).

O processo de conferência (check-out) está ligado ao sistema de gestão de mercadorias, e tem a função de completar a verificação geral dos materiais e encaminhar ao processo de emissão de nota fiscal e fatura - expedição. (MCFarlane \& Sheffi, 2003; Loebbecke \& Palmer, 2006). Na expedição, recebem-se os materiais separados, realizam-se as verificações de quantidade e especificações e, por fim, emitem-se as faturas e carregam-se os pedidos (Rouwenhorst et al., 2000; Hamdan \& Rogers, 2008). Ao serem carregados em um transportador, os pedidos deixam o armazém através das docas de expedição (Koster et al., 2007).

Armazenagem e embalagens relacionam-se em vários aspectos. $\mathrm{O}$ desempenho do armazenamento depende do desempenho das embalagens (Chan et al., 2006). Se, por um lado, a embalagem protege durante o transporte e manuseio interno, por outro lado, se não for adequadamente projetada, pode reduzir a eficiência da operação (Maia, 2001). Recentemente, principalmente associada a técnicas de sensoriamento eletrônico, a embalagem passou a integrar sistemas de informação e comunicação (Niemelä-Nyrhinen \& Uusitalo, 2013), reportando automaticamente informações logísticas, tais como: volume, peso, quantidade e dimensões (Nilsson et al., 2013).

\subsection{Impacto ambiental de embalagens e a pegada de carbono}

Segundo a ABNT (2004), impacto ambiental significa qualquer mudança no ambiente, quer adversa ou benéfica, inteira ou parcialmente resultante das atividades, produtos ou serviços de uma organização. Para que um impacto ambiental ocorra, é necessária a presença simultânea de três fatores: a fonte geradora; o veículo ou meio de propagação; e o alvo a ser impactado (Xavier \& Corrêa, 2013).

Embalagens produzem impactos ambientais que podem ser significativos. Segundo a ABRELPE (2012), a quantidade de resíduos sólidos produzidos pelo consumo das famílias brasileiras cresceu mais de $200 \%$ em trinta anos, chegando a cerca de 1.500 gramas por dia por pessoa. Deste total, cerca de metade corresponde a resíduos de papel, papelão, vidro, metálicas ou madeira. Importante fração desta parte corresponde a embalagens. Outra parcela de tamanho considerável é produzida por embalagens descartadas na indústria. Segundo o PNRS (Brasil, 2012), o consumo de matérias-primas para a confecção de embalagens em 2008 foi de 4.154 mil toneladas de papel e papelão, 886 mil toneladas de aço, $782 \mathrm{mil}$ toneladas de plástico e 1.041 mil toneladas de vidro. Considerando que menos de $2 \%$ dos resíduos sólidos são retornados por cooperativas, sendo o restante destinado a aterros sanitários, o consumo de embalagens no Brasil tem impacto ambiental significativo. Em síntese, o uso de embalagens descartáveis gera grande quantidade de resíduos e contribui para a saturação de aterros e para a escassez de novos materiais (González-Torre et al., 2004).

Alguns princípios de controle do impacto ambiental de embalagens foram propostos: (i) reduzir o volume e o peso das embalagens; (ii) reutilizar embalagens na função original; (iii) remanufaturar componentes gerando outros produtos; (iv) reciclar resíduos por meio de cooperativas, produzindo matéria-prima ou energia para outras indústrias; e (v) usar materiais degradáveis, não sobrecarregando aterros sanitários (Zhang \& Zhao, 2012).

Uma das maneiras de avaliar impactos ambientais, não apenas de embalagens, é a pegada de carbono (Carbon Footprint). A pegada de carbono é uma medida da quantidade total de emissões de óxido de carbono causada direta ou indiretamente por uma atividade ou acumulada ao longo do ciclo de vida de um produto (Chakraborty \& Roy, 2013). A pegada de carbono é uma medida das emissões de gases de efeito estufa, surgida a partir da necessidade de medir e comunicar o quanto uma atividade ou produto provoca alterações climáticas (Eriksson et al., 2010). O gás de efeito estufa mais importante é o dióxido de carbono $\left(\mathrm{CO}_{2}\right)$, mas outros gases, como o metano $\left(\mathrm{CH}_{4}\right)$ e o óxido nitroso $\left(\mathrm{N}_{2} \mathrm{O}\right)$ também contribuem para mudanças climáticas.

Várias metodologias foram propostas para o cálculo da pegada de carbono. As mais comuns são: a DEFRA (Department for Environment, Food \& Rural Affairs); a PAS 2050 (Publicy Available Specification 2050); e a GHG (Greenhouse Gas Protocol). A DEFRA tem por base os fatores de emissão específicos do Reino Unido. A PAS 2050 foi desenvolvida pela British Standards Institution (BSI), copatrocinada pela Carbon Trust e a DEFRA. A GHG fornece normas e diretrizes sobre as emissões de gases de efeito de estufa, abrangidos pelo Protocolo de Kyoto, como o $\mathrm{CO}_{2}, \mathrm{CH}_{4}, \mathrm{~N}_{2} \mathrm{O}, \mathrm{HFCs}$, PFCs e $\mathrm{SF}_{6}$ e foi desenvolvida pelo World Resources Institute (WRI) e o World Business Council for Sustainable Development (WBCSD) (Amorim, 2013).

A medição da pegada de carbono pode e deve ser acompanhada por ações de compensação ambiental. A compensação pode ser de quatro tipos: sequestro biológico de $\mathrm{CO}_{2}$; substituição de energia fóssil por renovável; aumento de eficiência energética; e redução das emissões não isentas de $\mathrm{CO}_{2}$ (Ramseur, 2008). Um exemplo é o plantio de novas árvores, o 
que retira carbono da atmosfera e o reincorpora à vegetação (Kageyama et al., 2008).

\section{Metodologia}

O método de pesquisa foi o estudo de caso único. A pesquisa foi feita no primeiro semestre de 2013.

Um estudo de caso é uma investigação empírica que investiga, porém sem alterar, um fenômeno contemporâneo dentro de seu contexto e dentro de limites, especialmente quando os limites entre o fenômeno e o contexto não são claramente definidos ou evidentes (Yin, 2010). O uso de vários métodos de coleta de dados pode trazer riqueza e flexibilidade para o processo de investigação em geral, tornando o estudo de caso particularmente útil na pesquisa de um fenômeno com certa complexidade (Dubé \& Paré, 2003). Para confiabilidade dos achados, o estudo de caso pode e deve se valer de múltiplas fontes, tais como entrevistas, observações de campo, e materiais de arquivos. Seu principal objetivo é fornecer descrições profundas de um objeto e elementos suficientes para, após observações repetidas, gerar hipóteses de pesquisa (Eisenhardt, 1989). A repetição e a regularidade de achados podem contribuir para a compreensão do objeto de estudo e para gerar o chamado caso crítico: aquele que pode comprovar ou desmentir uma eventual futura teoria gerada por casos (Eisenhardt \& Graebner, 2007).

Em estudos de caso, pode ser de interesse desenvolver construtos teóricos para organizar a coleta de dados e estabelecer o nível em que ocorrerão as generalizações dos resultados da pesquisa (Woodside \& Wilson, 2003). Para esta investigação, elaborou-se uma estrutura de pesquisa baseada em construtos encontrados na literatura: embalagem, impacto ambiental e armazenagem.

Embalagem foi dividida em: requisitos e funções (Williams et al., 2008; Veludo, 2004; Pelegrini, 2005; Bramklev, 2009; Azzi et al., 2012; García-Arca et al., 2014), classificação (Gustafsson et al., 2005) e características construtivas e normativas do papelão (Abbès \& Guo, 2010; ABNT, 2008; ABPO, 2014); custos (Verghese \& Lewis, 2007; Arvidsson \& Carlen, 2012); e ganhos econômicos, ambientais (Pelegrini, 2005; Silva et al., 2013; Chen et al., 2011) e logísticos (Adlmaier \& Sellitto, 2007; Baker \& Canessa, 2009).

Impacto ambiental foi dividido em: controle ambiental de embalagens (Zhang \& Zhao, 2012; ABRELPE, 2012; Xavier \& Corrêa, 2013; Brasil, 2012; ABNT, 2004; González-Torre et al., 2004); medição pela pegada de carbono (Amorim, 2013; Chakraborty \& Roy, 2013; Eriksson et al., 2010); e compensação ambiental (Kageyama et al., 2008; Ramseur, 2008).

Armazenagem foi dividida em: processos de armazenamento (Gong \& Koster, 2011; Pohl et al., 2011; Aly, 2010; Gu et al., 2010; Hamdan \& Rogers, 2008; Gu et al., 2007; Koster et al., 2007; Rouwenhorst et al., 2000); separação de pedidos (Bukchin et al., 2012; Van Nieuwenhuyse \& Koster, 2009; Parikh \& Meller, 2008; Koster et al., 2007; Lin \& Lu, 1999); e interações entre armazenagem e embalagem (Niemelä-Nyrhinen \& Uusitalo, 2013; Nilsson et al., 2013; Chan et al., 2006; Maia, 2001).

A Figura 1 mostra o modelo teórico que baseou a pesquisa.

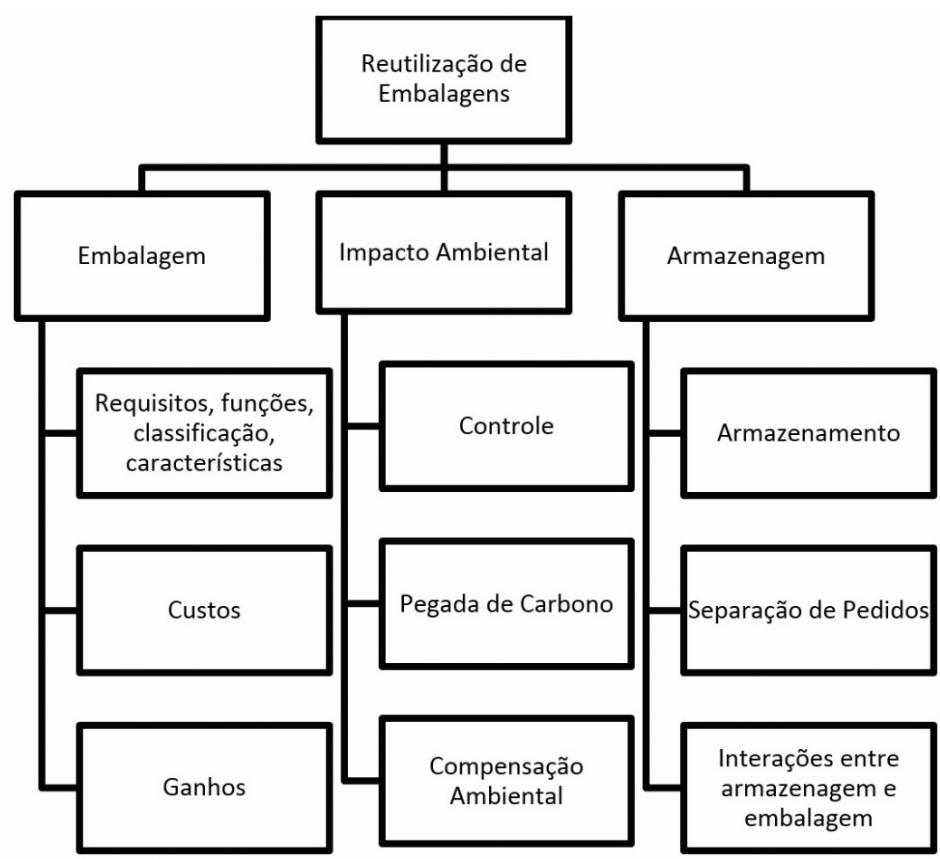

Figura 1. Modelo de pesquisa. Fonte: Elaborado pelos autores. 


\subsection{Método de trabalho}

Com base no referencial teórico, foi elaborado um protocolo de pesquisa direcionado à empresa estudada, conforme Quadro 1. Para validade e confiabilidade dos resultados, foram consideradas múltiplas fontes de evidência como entrevistas, relatórios e documentações relacionadas (Gibbert \& Ruigrok, 2010). O entrevistado foi selecionado considerando seu conhecimento em relação ao tema investigado. Foi entrevistado o diretor de operações da empresa, com formação superior e especialização em gestão de operações, que atua na empresa há mais de cinco anos e em operações há mais de quinze anos. A entrevista teve duração de cerca de quarenta e cinco minutos. Também foram realizadas análises dos processos e visitas técnicas com duração de uma hora em cada processo, guiadas por operadores dos processos de recebimento, armazenagem, abastecimento, picking, consolidação e conferência de pedidos (check-out). Nas visitas foi utilizada a técnica de observação não participante. Foram coletados dados originados de relatórios de custos e consumos mensais gerados pelo ERP da empresa, indicadores de compras de embalagens, fornecidos pela área de compras, formulários de endereçamentos, números de posições, números de SKUs ativos, fornecidos pela área de logística, e documentos sobre a frota, área física do armazém, e peso específico de embalagens de papelão.

\subsection{Objeto de estudo}

A pesquisa foi realizada em uma empresa de distribuição de materiais corporativos, fundada em 2007, em São Leopoldo, no Rio Grande do Sul. O setor de distribuição faturou mais de um bilhão de reais em 2013, empregando mais de trezentas e trinta mil pessoas (ABAD, 2014).

A empresa está instalada em uma planta de $6.500 \mathrm{~m}^{2}$ em terreno de $30.000 \mathrm{~m}^{2}$, e atua em comércio e distribuição de mais de 24.000 itens para o mercado corporativo: i) Office/Infoware: materiais como canetas, pastas, papéis sulfite A4, cartuchos e toners para impressão, pen-drives, cartões de memória; ii) EPIs/ Uniformes: equipamentos de segurança individuais e coletivos, uniformes personalizados; iii) Consumíveis/ Descartáveis: produtos perecíveis para coffee-break, descartáveis como copos plásticos, sacos de lixo; iv) Ferragem/Jardinagem: ferramentas, equipamentos, peças e acessórios; v) Higiene/Limpeza: materiais utilizados para higiene pessoal e produtos de limpeza pesada, industrial e profissional; vi) Coletores de Resíduos: produtos específicos para a coleta seletiva e de resíduos sólidos; vii) Material Elétrico: extensões, fios e lâmpadas; e viii) Personalizados: materiais operacionais, presentes, brindes personalizados.

A área de operações se divide em logística interna, responsável pela armazenagem e movimentação dos produtos no $\mathrm{CD}$, e distribuição, que responde pela entrega dos pedidos aos clientes. A distribuição pode ser terceirizada por transportadores ou por frota própria, possuindo 25 veículos de diversos tamanhos e modelos para o atendimento a clientes em um raio de $150 \mathrm{~km}$ do CD. A estrutura de armazenagem e movimentação é gerenciada por um sistema WMS (Warehouse Management System) e fisicamente está dividida em três armazéns: dois mezaninos e estoque central, com mais de 8.500 posições de armazenagem e dezessete corredores para movimentação de materiais.

\section{Resultados}

As informações a seguir foram obtidas por entrevista com o diretor de operações.

O projeto de reutilização de embalagens de papelão surgiu devido ao acúmulo de embalagens usadas e ao custo mensal na compra de embalagens novas para entregas.

Anteriormente, a entrada era realizada pela equipe de operadores de armazenamento, que levava os itens até o local indicado pelo WMS, sem retirar os produtos da embalagem. A retirada era realizada pela equipe de separação de pedidos. Por falta de procedimentos adequados e por serem medidos por produtividade, estes operadores abriam as embalagens com estiletes, rasgando-as, o que por vezes inutilizava também os produtos. As embalagens em sua quase totalidade eram sucateadas, gerando resíduos sólidos.

A Figura 2 representa o fluxo das embalagens de papelão desde os fornecedores até o envio aos clientes como ficou após a reutilização.

A empresa não controlava o consumo mensal de embalagens novas, não havendo procedimento de controle e gestão do estoque e consumo destas embalagens. Como não havia controle de consumo, a empresa limitava-se a repor o estoque periodicamente. Um fator que elevava o custo de embalagens era a estratégia de separação de pedidos adotada, o picking por zona. As tarefas são geradas automaticamente pelo WMS para cada corredor, exigindo uma embalagem para cada tarefa específica de cada corredor. As caixas eram identificadas com a numeração do pedido e enviadas para a área de conferência de pedidos (check-out).

Os fluxogramas das Figuras 3 e 4 sistematizam o entendimento sobre os procedimentos antes da reutilização. As informações das figuras foram obtidas por visitas técnicas com o acompanhamento de operadores de armazenamento e de separação de pedidos (picking) e também por observação não participante.

Antes do início do projeto, foram mensurados por três meses o consumo e o custo mensal com embalagens novas, apresentadas na Tabela 1. As informações da tabela foram obtidas por consulta ao relatório de 
Quadro 1. Protocolo de pesquisa.

\begin{tabular}{|c|c|c|}
\hline Pergunta Geral & Tópicos a explorar & Autores \\
\hline \multirow{5}{*}{$\begin{array}{l}\text { Embalagem: } \\
\text { Como as embalagens } \\
\text { impactam na } \\
\text { operação logística da } \\
\text { empresa? }\end{array}$} & $\begin{array}{l}\text { Como surgiu o projeto de reutilização das } \\
\text { embalagens? Qual o efeito motivador? } \\
\text { Econômico? Ambiental? }\end{array}$ & \multirow{3}{*}{$\begin{array}{l}\text { Williams et al., 2008; Veludo, 2004; } \\
\text { Gustafsson et al., 2005; Pelegrini, 2005; } \\
\text { ABNT, 2008; Bramklev, 2009; Abbès \& Guo } \\
\text { 2010; Azzi et al., 2012; Abpo, 2014; García- } \\
\text { Arca et al., } 2014\end{array}$} \\
\hline & $\begin{array}{l}\text { Quais são os requisitos, funções, } \\
\text { características construtivas e normativas das } \\
\text { embalagens de papelão adquiridas novas } \\
\text { pela empresa? }\end{array}$ & \\
\hline & $\begin{array}{l}\text { As embalagens oriundas de fornecedores } \\
\text { possuem os mesmos requisitos das } \\
\text { compradas? Se não, como é feita a triagem? }\end{array}$ & \\
\hline & $\begin{array}{l}\text { Quais são os custos das embalagens de } \\
\text { papelão adquiridas novas pela empresa? } \\
\text { Como eles são mensurados? }\end{array}$ & $\begin{array}{l}\text { Verghese \& Lewis, 2007; Arvidsson \& } \\
\text { Carlen, } 2012\end{array}$ \\
\hline & $\begin{array}{l}\text { Quais os ganhos econômicos, ambientais } \\
\text { e logísticos do projeto? Como estes foram } \\
\text { mensurados? }\end{array}$ & $\begin{array}{l}\text { Pelegrini, 2005; Adlmaier \& Sellitto, 2007; } \\
\text { Baker \& Canessa, 2009; Chen et al., 2011; } \\
\text { Silva et al., } 2013\end{array}$ \\
\hline \multirow{3}{*}{$\begin{array}{l}\text { Impacto Ambiental: } \\
\text { Como as embalagens } \\
\text { de papelão usadas na } \\
\text { empresa impactam o } \\
\text { meio ambiente? }\end{array}$} & $\begin{array}{l}\text { Quais são os controles ambientais existentes } \\
\text { sobre as embalagens de papelão e como eles } \\
\text { são mensurados? }\end{array}$ & $\begin{array}{l}\text { ABNT, 2004, González-Torre et al., 2004; } \\
\text { Zhang \& Zhao, 2012; ABRELPE, 2012; } \\
\text { Xavier \& Corrêa, } 2013\end{array}$ \\
\hline & $\begin{array}{l}\text { O que é pegada de carbono, qual a pegada } \\
\text { das embalagens e como é mensurada? }\end{array}$ & $\begin{array}{l}\text { Eriksson et al., 2010; Amorim, 2013; } \\
\text { Chakraborty \& Roy, } 2013\end{array}$ \\
\hline & $\begin{array}{l}\text { O que é compensação de carbono, qual a } \\
\text { atual situação e como é mensurada? }\end{array}$ & Kageyama et al., 2008; Ramseur, 2008 \\
\hline \multirow{6}{*}{$\begin{array}{l}\text { Armazenagem: } \\
\text { Como as embalagens } \\
\text { de papelão impactam } \\
\text { os processos } \\
\text { operacionais do } \\
\text { Armazém? }\end{array}$} & $\begin{array}{l}\text { Como é realizado o processo de recebimento } \\
\text { de materiais? Qual o impacto das } \\
\text { embalagens de papelão nesse processo? }\end{array}$ & $\begin{array}{l}\text { Niemelä-Nyrhinen \& Uusitalo, 2013; } \\
\text { Nilsson et al., 2013; Gong \& Koster, 2011; } \\
\text { Gu et al., 2007, 2010; Koster et al., 2007; } \\
\text { Rouwenhorst et al., } 2000\end{array}$ \\
\hline & $\begin{array}{l}\text { Como é realizado o processo de } \\
\text { armazenagem de materiais na empresa? } \\
\text { Qual o impacto das embalagens de papelão } \\
\text { nesse processo? }\end{array}$ & $\begin{array}{l}\text { Niemelä-Nyrhinen \& Uusitalo, 2013; } \\
\text { Nilsson et al., 2013; Gong \& Koster, 2011; } \\
\text { Pohl et al., 2011; Aly, 2010; Gu et al., 2010; } \\
\text { Hamdan \& Rogers, 2008; Gu et al., 2007; } \\
\text { Koster et al., 2007; Chan et al., 2006; Maia, } \\
\text { 2001; Rouwenhorst et al., } 2000\end{array}$ \\
\hline & $\begin{array}{l}\text { Como é realizado o processo de } \\
\text { abastecimento de área de picking na } \\
\text { empresa? Qual o impacto das embalagens de } \\
\text { papelão nesse processo? }\end{array}$ & $\begin{array}{l}\text { Niemelä-Nyrhinen \& Uusitalo, 2013; } \\
\text { Nilsson et al., 2013; Gong \& Koster, 2011; } \\
\text { Pohl et al., 2011; Aly, 2010; Gu et al., 2010; } \\
\text { Hamdan \& Rogers, 2008; Gu et al., 2007; } \\
\text { Koster et al., 2007; Chan et al., 2006; Maia, } \\
\text { 2001; Rouwenhorst et al., } 2000\end{array}$ \\
\hline & $\begin{array}{l}\text { Como é realizado o processo de picking na } \\
\text { empresa e como ele está definido? Qual o } \\
\text { impacto das embalagens de papelão nesse } \\
\text { processo? }\end{array}$ & $\begin{array}{l}\text { Niemelä-Nyrhinen \& Uusitalo, 2013; } \\
\text { Nilsson et al., 2013; Bukchin et al., 2012; } \\
\text { Van Nieuwenhuyse \& Koster, 2009; Parikh \& } \\
\text { Meller, 2008; Koster et al., 2007; Chan et al., } \\
\text { 2006; Maia, 2001; Lin \& Lu, } 1999\end{array}$ \\
\hline & $\begin{array}{l}\text { Como é realizado o processo de } \\
\text { consolidação da empresa? Qual o impacto } \\
\text { das embalagens de papelão nesse processo? }\end{array}$ & $\begin{array}{l}\text { Niemelä-Nyrhinen \& Uusitalo, 2013; } \\
\text { Nilsson et al., 2013; Gong \& Koster, 2011; } \\
\text { Shiau \& Lee, 2010; Chan et al., 2006; Maia, } \\
\text { 2001; Rouwenhorst et al., } 2000\end{array}$ \\
\hline & $\begin{array}{l}\text { Como é realizado o processo de Conferência } \\
\text { e Expedição de materiais na Empresa? Qual } \\
\text { o impacto das embalagens de papelão nesse } \\
\text { processo? }\end{array}$ & $\begin{array}{l}\text { Niemelä-Nyrhinen \& Uusitalo, 2013; } \\
\text { Nilsson et al., 2013; Hamdan \& Rogers, } \\
\text { 2008; Koster et al., 2007; Chan et al., 2006; } \\
\text { Loebbecke \& Palmer, 2006; McFarlane \& } \\
\text { Sheffi, 2003; Maia, 2001; Rouwenhorst et al., } \\
2000\end{array}$ \\
\hline
\end{tabular}

Fonte: Elaborado pelos autores. 
consumo de embalagens extraído do ERP, fornecido pelo diretor de operações da empresa.

Para possibilitar a reutilização das embalagens de papelão, era necessário garantir a integridade das embalagens recebidas, alterar as embalagens para caixas retornáveis (unitizadoras) e consolidar os pedidos antes da conferência. Para garantir a integridade, a equipe de armazenamento passou a fazer a retirada de produtos das embalagens não mais no armazenamento, mas no momento da separação. A equipe também ficou responsável pelo recolhimento e segregação das embalagens por tamanhos e pelo
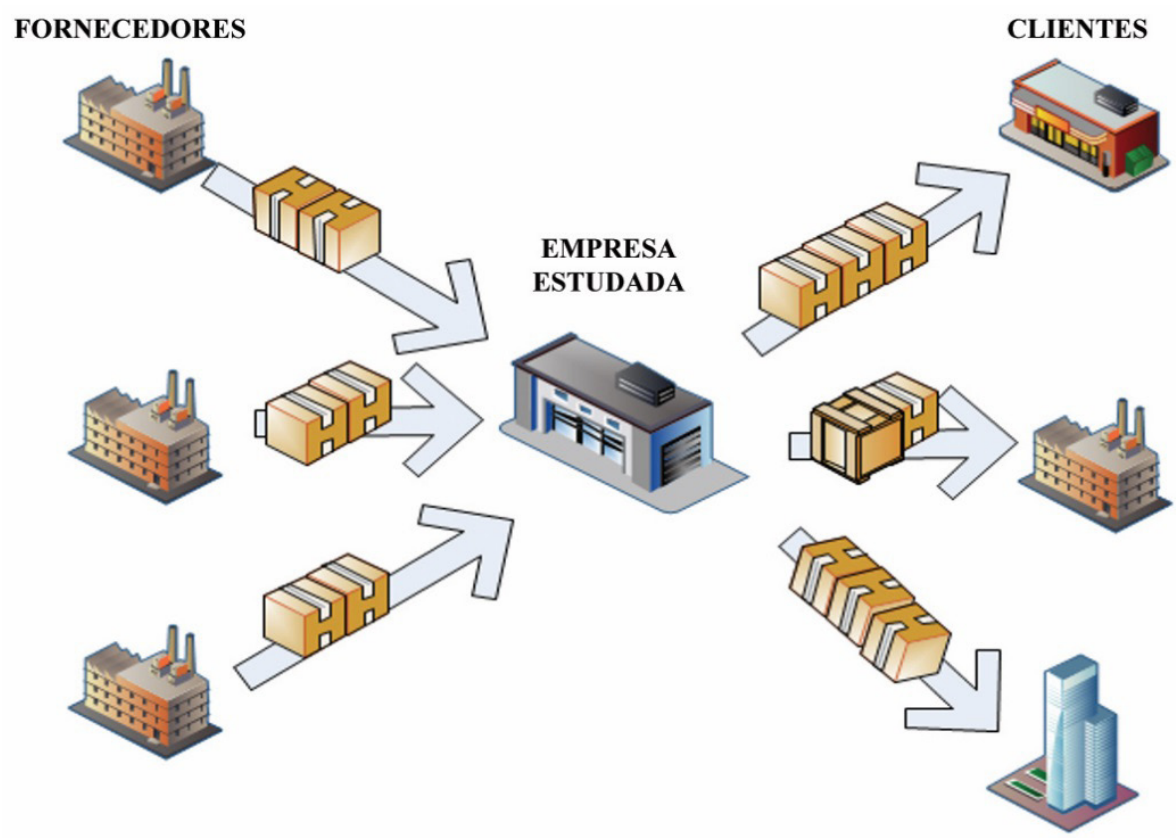

Embalagem enviada pelo fornecedor

Embalagem nova

Figura 2. Fluxo das embalagens de papelão. Fonte: Elaborado pelos autores.

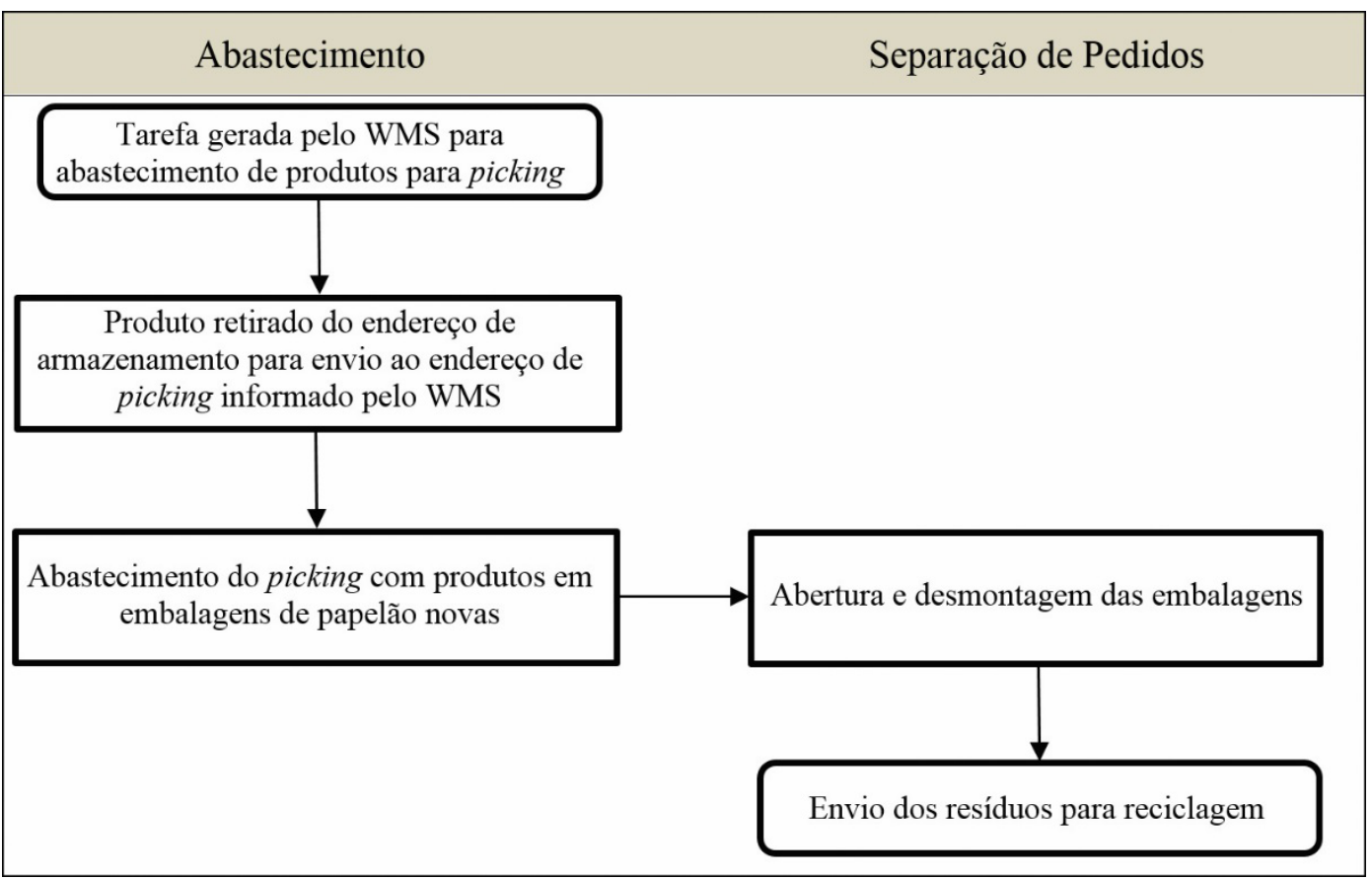

Figura 3. Fluxo das embalagens de papelão antes da reutilização. Fonte: Elaborado pelos autores. 


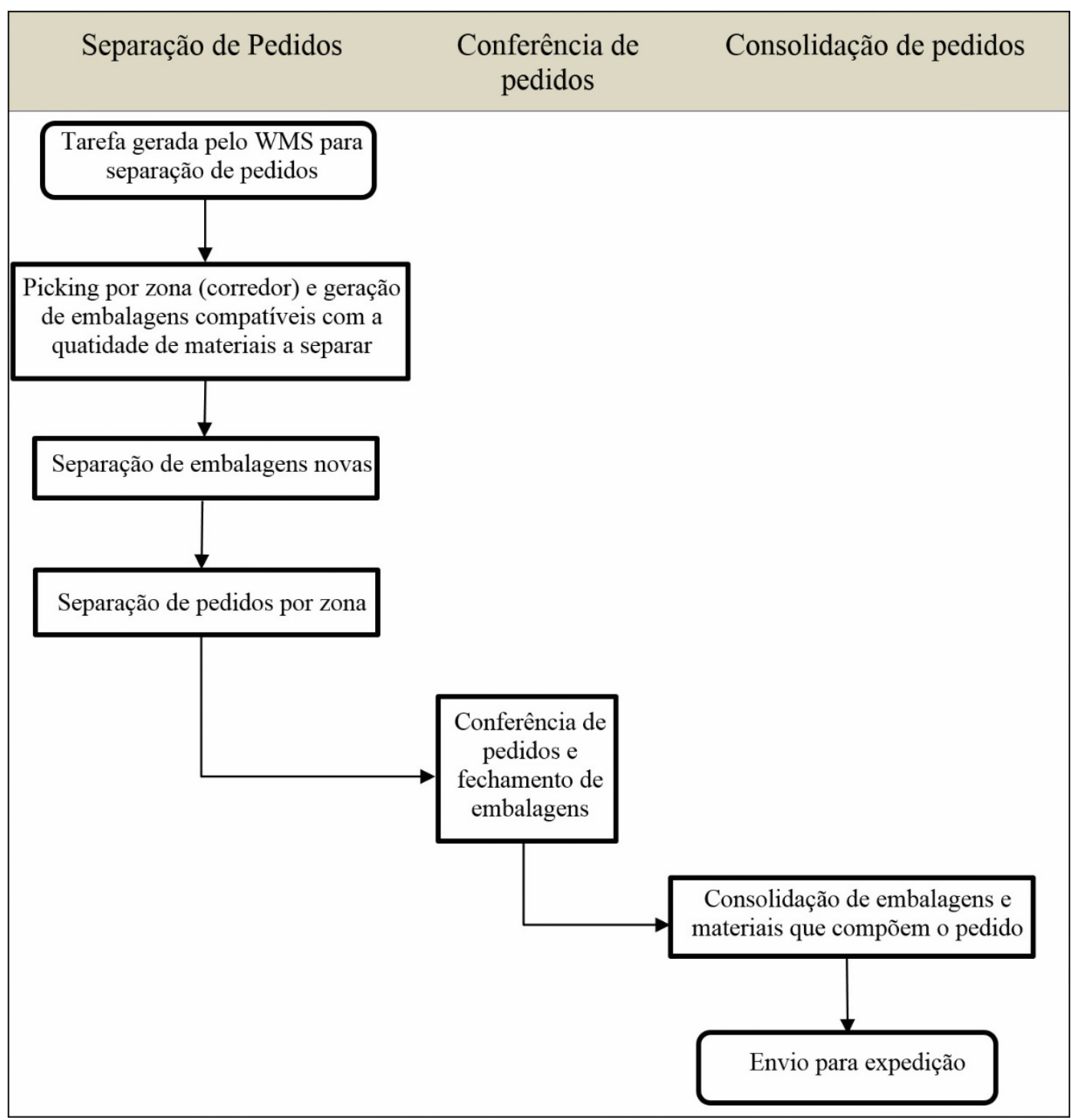

Figura 4. Fluxo de utilização de embalagens novas no processo de picking. Fonte: Elaborado pelos autores.

Tabela 1. Informações antes da reutilização.

\begin{tabular}{lccccc}
\hline \multicolumn{1}{c}{ Mês } & Quantidade & Custo (R\$) & Custo médio & $\begin{array}{c}\text { Consumo de } \\
\text { papelão (kg) }\end{array}$ & $\begin{array}{c}\text { Consumo médio } \\
\text { (kg/unid.) }\end{array}$ \\
\hline Abril/2013 & 33.548 & 44.585 & 1,33 & 16.235 & 0,48 \\
Maio/2013 & 18.221 & 27.703 & 1,52 & 10.078 & 0,55 \\
Junho/2013 & 31.152 & 42.773 & 1,37 & 15.279 & 0,49 \\
Média trimestral & 27.640 & 38.354 & 1,41 & 13.864 & 0,51 \\
\hline
\end{tabular}

seu envio ao setor de conferência de pedidos, no qual serão usadas no acondicionamento final dos produtos a distribuir.

A Figura 5 ilustra o novo processo. As informações da figura foram obtidas por entrevista com operadores de armazenamento e por observação não participante.

Foi necessário mudar o processo de separação de pedidos, antes encerrado e embalado por zona, e agora embalado apenas uma vez, após a consolidação. Para as transferências parciais até a zona de conferência, foram usadas caixas plásticas existentes na empresa. Finalizado o pedido, a área de conferência recebe via sistema o número e a localização, na área de consolidação, do pedido a ser conferido. O pedido é então conferido e embalado nas embalagens reutilizadas. Para cerca de 5\% dos clientes, seguem 


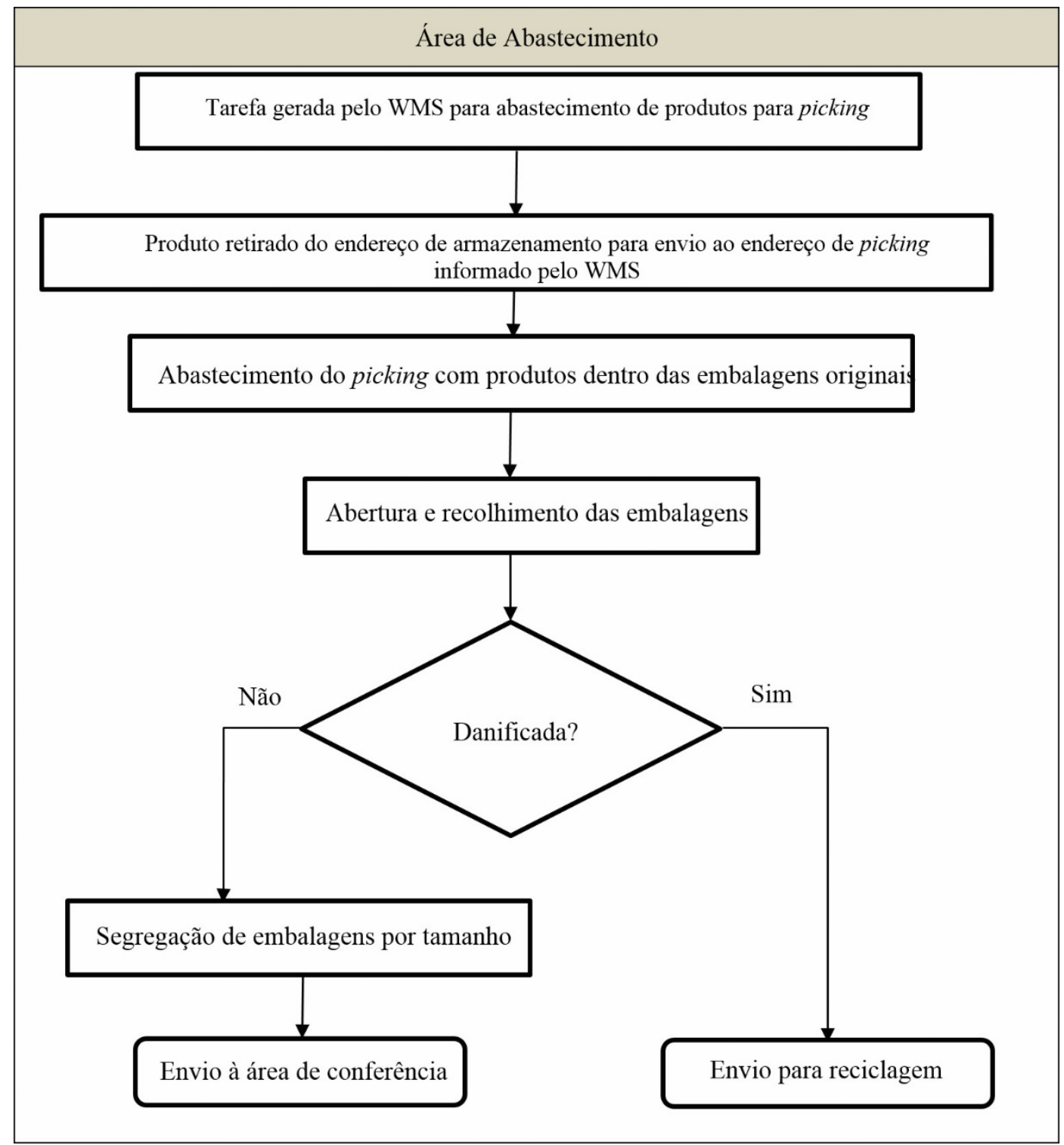

Figura 5. Fluxo de utilização de embalagens de papelão recebidas de fornecedores a serem reutilizadas para unitizar pedidos a serem entregues a clientes. Fonte: Elaborado pelos autores.

sendo necessárias embalagens novas. Finalizada a conferência, as embalagens seguem para expedição, faturamento e despacho aos clientes.

A Figura 6 sintetiza a reutilização. As informações da figura foram obtidas por entrevistas com operadores de separação, conferência e consolidação de pedidos, e por observação não participante.

A implantação foi finalizada no fim de julho de 2013.

\section{Discussão}

A Tabela 2 apresenta a continuidade da mensuração.

Observam-se reduções de 85,86 e 87 pontos percentuais, respectivamente na quantidade, no custo de embalagens, e no consumo de papelão entre o mês de novembro, a última medição disponível, e a média do trimestre anterior à reutilização. Também houve redução de 11 e de 17 pontos percentuais, respectivamente no custo médio e no consumo médio das embalagens, relacionado principalmente à racionalização e à redução de importância que as embalagens passaram a ter na estratégia da empresa, o que tem permitido compras em condições mais favoráveis de preço, prazo de entrega e tamanho de lote. Considere-se que a empresa usa embalagens com papelão simples e duplo.

Para a análise dos benefícios ambientais, considerou-se a quantidade de papelão reduzido no período. No trimestre anterior à reutilização, houve consumo médio mensal de 13.864 quilogramas de papelão. Em novembro de 2013, houve consumo 


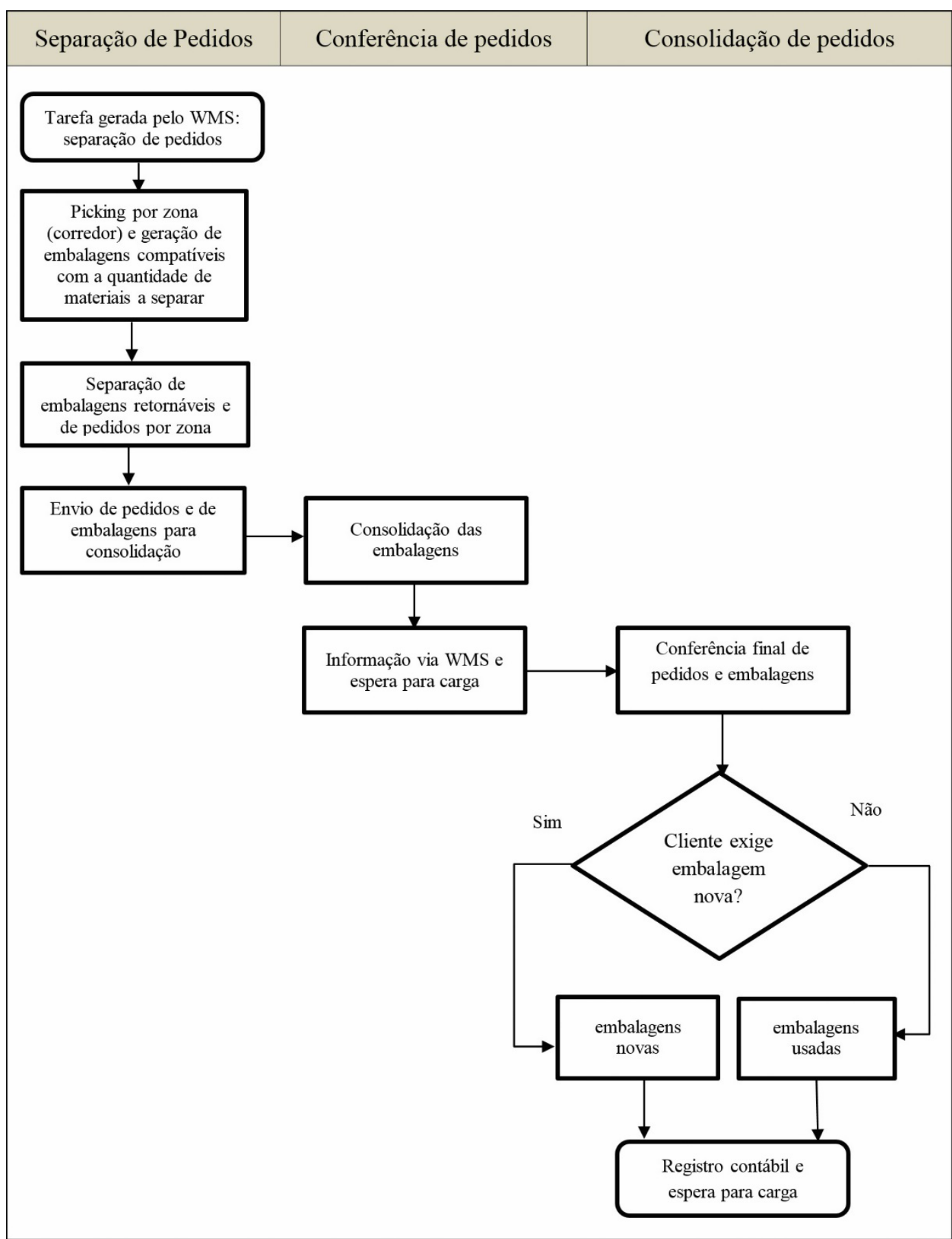

Figura 6. Fluxo operacional de pedidos para a reutilização das embalagens de papelão. Fonte: Elaborado pelos autores.

mensal de 1.767 quilogramas de papelão. A diferença foi de 12.097 quilogramas mensais de papelão.

Para calcular a pegada de carbono e a compensação ambiental resultantes, buscou-se uma calculadora de carbono que analise o consumo de papelão. A mais próxima que se encontrou usa papel sulfite como base. Usando calculadora de carbono disponibilizada pela Secretaria do Meio Ambiente do Estado de Goiás (Goiás, 2014), a redução de consumo de embalagens reduziu a pegada de carbono e a necessidade de compensação ambiental (quantidades de árvores a serem plantadas anualmente) da empresa conforme os dados da Tabela 3 .

Observa-se redução de 87,3 pontos percentuais na pegada de carbono e por consequência na quantidade de árvores que eventualmente deveriam ser plantadas para compensar o impacto ambiental causado pelo uso de embalagens de papelão. Os benefícios ambientais 
Tabela 2. Informações após a reutilização.

\begin{tabular}{lccccc}
\hline \multicolumn{1}{c}{ Mês } & Quantidade & Custo (R\$) & Custo médio & $\begin{array}{c}\text { Consumo de } \\
\text { papelão (kg) }\end{array}$ & $\begin{array}{c}\text { Consumo médio } \\
\text { (kg/unid.) }\end{array}$ \\
\hline Julho/13 & 24.588 & 24.309 & 0,99 & 8.690 & 0,35 \\
Agosto/13 & 9.663 & 10.235 & 1,06 & 3.662 & 0,38 \\
Setembro/13 & 5.629 & 7.029 & 1,25 & 2.568 & 0,46 \\
Outubro/13 & 4.450 & 6.854 & 1,54 & 2.471 & 0,56 \\
Novembro/13 & 4.170 & 5.247 & 1,26 & 1.767 & 0,42 \\
Relação novembro/ média & $15 \%$ & $14 \%$ & $89 \%$ & $13 \%$ & $83 \%$ \\
trimestral anterior & & & & & \\
\hline
\end{tabular}

Tabela 3. Benefícios ambientais da reutilização.

\begin{tabular}{lcc}
\hline \multicolumn{1}{c}{ Mês } & $\begin{array}{c}\text { Pegada de Carbono } \\
\left(\mathbf{C O}_{2} / \mathbf{a n o}\right) \mathbf{~ e m ~} \mathbf{~ k g}\end{array}$ & $\begin{array}{c}\text { Compensação ambiental } \\
\text { (árvores/ano) }\end{array}$ \\
\hline Média trimestral anterior & 27.730 & 175 \\
Novembro/13 & 3.530 & 22,2 \\
Relação novembro/ média trimestral anterior & $12,7 \%$ & $12,7 \%$ \\
\hline
\end{tabular}

Quadro 2. Protocolo de pesquisa.

\begin{tabular}{|c|c|c|}
\hline Constructos & Conceitos & Achados \\
\hline \multirow{3}{*}{ Embalagem } & $\begin{array}{l}\text { Requisitos, funções, } \\
\text { classificação, } \\
\text { características }\end{array}$ & $\begin{array}{l}\text { Exercem funções Logísticas e Ambientais; Terciárias, quanto } \\
\text { à classificação; com características construtivas de papelão } \\
\text { ondulado de cartão duplo, conforme NBR } 5985 .\end{array}$ \\
\hline & Custos & Redução de $86 \%$ na compra de embalagens novas de papelão. \\
\hline & Ganhos & $\begin{array}{l}\text { Ambientas (redução na pegada de carbono e compensação } \\
\text { ambiental) e Econômicos (redução dos custos com embalagens } \\
\text { de papelão novas). }\end{array}$ \\
\hline \multirow{3}{*}{ Impacto Ambiental } & Controle & $\begin{array}{l}\text { Alta Reciclagem dos resíduos por meio de cooperativas (antes } \\
\text { do projeto); Reutilização de embalagens na função original no } \\
\text { envio de materiais a clientes. }\end{array}$ \\
\hline & Pegada de carbono & Redução na pegada de carbono de $87,3 \%$. \\
\hline & Compensações & $\begin{array}{l}\text { Compensação Ambiental por meio de plantação de árvores e } \\
\text { redução de } 87,3 \% \text {. }\end{array}$ \\
\hline \multirow{3}{*}{ Armazenagem } & Armazenamento & $\begin{array}{l}\text { Recebimento e armazenamento (com lógica de localização } \\
\text { aleatória), consolidação e expedição: gerenciados pelo WMS. }\end{array}$ \\
\hline & Separação & $\begin{array}{l}\text { Estratégia por zona; acondicionamento dos materiais em } \\
\text { embalagens retornáveis (plásticas) no ambiente interno do } \\
\text { armazém até enviar ao setor de consolidação. }\end{array}$ \\
\hline & Relação com embalagens & $\begin{array}{l}\text { Funções de proteção, unitização e comunicação (etiquetas para } \\
\text { rastreamento) em todas as etapas do processo, contendo as } \\
\text { informações de peso, volumes, quantidades e validade do lote. }\end{array}$ \\
\hline
\end{tabular}

Fonte: Elaborado pelos autores.

observados na reutilização de embalagens não implicaram perda de interesse econômico.

Os resultados apontam para um conjunto de elementos que podem auxiliar as empresas de distribuição de suprimentos na reutilização das embalagens recebidas de seus fornecedores para a entrega de produtos aos seus clientes, gerando ganhos financeiros e ambientais. O Quadro 2 sintetiza os resultados, segundo o modelo teórico de pesquisa.

\section{Conclusão}

Este artigo respondeu à seguinte questão de pesquisa: Como a reutilização de embalagens de papelão pode impactar a operação de uma empresa de distribuição de suprimentos corporativos? O impacto ocorre em dois campos: econômico e ambiental. No campo econômico, observou-se uma redução de mais de $80 \%$ no custo e na quantidade de embalagens novas. 
No campo ambiental, uma redução de mais de $12 \%$ na pegada de carbono. Com a reutilização de embalagens recebidas de fornecedores, a empresa não alterou seu desempenho de entregas de pedidos, tanto em pontualidade como em integridade. Foram observados os seguintes benefícios: redução de compras de embalagens novas, redução do consumo de papelão de embalagens da linha de pedido faturado (em kg de papelão consumidos), redução da Pegada de Carbono e redução da necessidade de compensação ambiental.

A análise baseou-se em dados fornecidos pela empresa e em entrevistas com o diretor de operações e com operadores dos processos de recebimento, armazenagem, abastecimento, separação (picking), consolidação e conferência de pedidos (check-out). A empresa opera com cerca de 24.000 itens diversos e ativos.

Futuras pesquisas podem incluir um comparativo deste reaproveitamento em empresas de outros segmentos, que possam reutilizar as embalagens recebidas dos fornecedores para o envio de seus produtos aos clientes e também podem avaliar a possibilidade de implementação desse processo em empresas que tenham atuação internacional, abrangendo aspectos legais e de conservação da embalagem reutilizada.

\section{Referências}

Abbès, B., \& Guo, Y. (2010). Analytic homogenization for torsion of orthotropic sandwich plates: application to corrugated cardboard. Composite Structures, 92(3), 699706. http://dx.doi.org/10.1016/j.compstruct.2009.09.020.

Adlmaier, D., \& Sellitto, M. (2007). Embalagens retornáveis para transporte de bens manufaturados: um estudo de caso em logística reversa. Produção, 17(2), 395-406.

Aly, A. H. (2010). Order picking and storage using stackable pallets in a warehouse (Tese de doutorado). Clemson University: Clemson.

Amorim, D. (2013). Pegada de Carbono em uma empresa produtora de eletricidade de fontes renováveis (Dissertação de mestrado). Faculdade de Engenharia da Universidade do Porto, Portugal.

Arvidsson, S., \& Carlen, V. (2012). Environmental and Cost Analysis at Volvo Logistics Corporation Emballage: a study of the flow of L-packaging between producers, terminals and users in Europe and an evaluation of direct transports. Gothenburg: Division of Logistics and transportation, Department of Technology Management and Economics, Chalmers University of Technology. 65 p.

Associação Brasileira de Atacadistas e Distribuidores de Produtos Industrializados - ABAD. Recuperado em agosto de 2014, de http://www.abad.com.br/dados/ numeros.shtml.

Associação Brasileira de Empresas de Limpeza Pública e Resíduos Especiais - ABRELPE. (2012). Panorama de resíduos sólidos no Brasil. São Paulo. Recuperado em outubro de 2013, de http://www.abrelpe.org.br/ Panorama/panorama2012.pdf.

Associação Brasileira de Normas Técnicas - ABNT. (2004). NBR ISO 14001: sistemas de gestão ambiental, especificação e diretrizes para uso. Rio de Janeiro.

Associação Brasileira de Normas Técnicas - ABNT. (2008). NBR 5985: Embalagem de papelão ondulado: terminologia. Rio de Janeiro.

Associação Brasileira de Papelão Ondulado - ABPO. (2014). Estrutura do papelão ondulado. São Paulo. Recuperado em janeiro de 2014, de http://www.abpo. org.br/?page_id=1156.

Azzi, A., Battini, D., Persona, A., \& Sgarbossa, F. (2012). Packaging design: general framework and research agenda. Packaging Technology and Science, 25(8), 435-456. http://dx.doi.org/10.1002/pts.993.

Baker, P., \& Canessa, M. (2009). Warehouse design: a structured approach. European Journal of Operational Research, 193(2), 425-436. http://dx.doi.org/10.1016/j. ejor.2007.11.045.

Bramklev, C. (2009). On a proposal for a generic package development process. Packaging Technology and Science, 22(3), 171-186. http://dx.doi.org/10.1002/pts.850.

Brasil. Governo Federal. Ministério do Meio Ambiente. (2012). Plano Nacional de Resíduos Sólidos: PNRS. Versão pós audiências e consulta pública para conselhos nacionais. Brasília. Recuperado em março de 2014, de http://www.mma.gov.br/port/conama/reuniao/dir1529/ PNRS_consultaspublicas.pdf.

Bukchin, Y., Khmelnitsky, E., \& Yakuel, P. (2012). Optimizing a dynamic order-picking process. European Journal of Operational Research, 219(2), 335-346. http://dx.doi. org/10.1016/j.ejor.2011.12.041.

Chakraborty, D., \& Roy, J. (2013). Corporate carbon footprint accounting: estimating carbon footprint of an indian paperboard and paper production unit. International Journal of Business Insights \& Transformation, 6(1), 18-26.

Chan, F., Chan, H., \& Choy, K. (2006). A systematic approach to manufacturing packaging logistics. International Journal of Advanced Manufacturing Technology, 29(9-10), 1088-1101. http://dx.doi.org/10.1007/s00170005-2609-x.

Chen, J., Zhang, Y.-L., \& Sun, J. (2011). An overview of the reducing principle of design of corrugated box used in goods packaging. Procedia Environmental Sciences, 10(Pt B), 992-998.

Ciliberti, F., Pontrandolfo, P., \& Scozzi, B. (2008). Logistics social responsibility: Standard adoption and practices in Italian companies. International Journal of Production Economics, 113(1), 88-106. http://dx.doi.org/10.1016/j. ijpe.2007.02.049.

Dubé, L., \& Paré, G. (2003). Rigor in information systems positivist case research: current practices, trends, and 
recommendations. Management Information Systems Quarterly, 27(4), 597-635.

Eisenhardt, K. (1989). Building theories from case study research. Academy of Management Review, 14(4), 532-550.

Eisenhardt, K., \& Graebner, M. (2007). Theory building from cases: opportunities and challenges. Academy of Management Journal, 50(1), 25-32. http://dx.doi. org/10.5465/AMJ.2007.24160888.

Eriksson, E., Karlsson, P.-E., Hallberg, L., \& Jelse, K. (2010). Carbon footprint of cartons in Europe: carbon footprint methodology and biogenic carbon sequestration (pp. 1-59). Stockholm: IVL Swedish Environmental Research Institute.

García-Arca, J., González-Portela, A. T., \& Prado-Prado, J. C. (2014). Packaging as source of efficient and sustainable advantages in Supply chain management: an analysis of milk cartons. International Journal Production Management Engineering, 2(1), 15-22. http://dx.doi.org/10.4995/ijpme.2014.1860.

Gibbert, M., \& Ruigrok, W. (2010). The "what" and "how" of case study rigor: three strategies based on published work. Organizational Research Methods, 13(4), 710737. http://dx.doi.org/10.1177/1094428109351319.

Goiás. Secretaria do Meio Ambiente e dos Recursos Hídricos do Estado de Goiás - SEMARH. Calculadora de Carbono. Goiânia. Recuperado em janeiro de 2014, de http://www.semarh.goias.gov.br/site/calculadora.

Gong, Y., \& Koster, R. (2011). A review on stochastic models and analysis of warehouse operations. Logistics Research, 3(4), 191-205. http://dx.doi.org/10.1007/ s12159-011-0057-6.

González-Torre, P., Adenso-Díaz, B., \& Artiba, H. (2004). Environmental and reverse logistics policies in European bottling and packaging firms. International Journal of Production Economics, 88(1), 95-104. http://dx.doi. org/10.1016/S0925-5273(03)00181-6.

Gu, J., Goetschalckx, M., \& Mcginnis, F. (2007). Research on warehouse operation: A comprehensive review. European Journal of Operational Research, 177(1), 1-21. http://dx.doi.org/10.1016/j.ejor.2006.02.025.

Gu, J., Goetschalckx, M., \& Mcginnis, F. (2010). Research on warehouse design and performance evaluation: a comprehensive review. European Journal of Operational Research, 203(3), 539-549. http://dx.doi.org/10.1016/j. ejor.2009.07.031.

Gustafsson, K., Jönson, G., Smith, D., \& Sparks, L. (2005). Packaging logistics and retailers' profitability: an IKEA case study. In 13th Research Conference of the European Association for Education and Research in Commercial Distribution. Sweden: Lund University.

Hamdan, A., \& Rogers, J. (2008). Evaluating the efficiency of 3PL logistics operations. International Journal of Production Economics, 113(1), 235-244. http://dx.doi. org/10.1016/j.ijpe.2007.05.019.
Harrysson, A., \& Ristinmaa, M. (2008). Large strain elastoplastic model of paper and corrugated board. International Journal of Solids and Structures, 45(11-12), 3334-3352. http://dx.doi.org/10.1016/j. ijsolstr.2008.01.031.

Jabbour, C., \& Santos, F. (2008). The central role of human resource management in the search for sustainable organizations. International Journal of Human Resource Management, 19(12), 2133-2154. http:// dx.doi.org/10.1080/09585190802479389.

Kageyama, P., Oliveira, R., Moraes, L., Engel, V., \& Gandara, F. (2008). Restauração ecológica de ecossistemas naturais. Botucatu: FEPAF.

Kocabasoglu, C., Prahinski, C., \& Klassen, R. (2007). Linking forward and reverse supply chain investments: the role of business uncertainty. Journal of Operations Management, 25(6), 1141-1160. http://dx.doi.org/10.1016/j. jom.2007.01.015.

Koster, R., Le-Duc, T., \& Roodbergen, K. J. (2007). Design and control of warehouse order picking: a literature review. European Journal of Operational Research, 182(2), 481-501. http://dx.doi.org/10.1016/j.ejor.2006.07.009.

Levi, M., Cortesi, S., Vezzoli, C., \& Salvia, G. (2011). A comparative life cycle assessment of disposable and reusable packaging for the distribution of italian fruit and vegetables. Packaging Technology and Science, 24(7), 387-400. http://dx.doi.org/10.1002/pts.946.

Lin, C., \& Lu, I. (1999). The procedure of determining the order picking strategies in distribution center. International Journal of Production Economics, 60-61(1), 301-307. http://dx.doi.org/10.1016/S0925-5273(98)00188-1.

Loebbecke, C., \& Palmer, J. (2006). RFID becomes fashionable in the supply chain: the case of Kaufhof and Gerry Weber. In Proceedings of the Twelfth AMCIS: Americas Conference on Information Systems (pp. 18871894). Acapulco: Association for Information Systems.

Maia, W. (2001). O uso de embalagens reutilizáveis nos canais de exportação da Fiat (Dissertação de mestrado). Programa de Pós-Graduação em Engenharia de Produção da Universidade Federal de Santa Catarina, Florianópolis.

McFarlane, D., \& Sheffi, Y. (2003). The impact of automatic identification on supply chain operations. The International Journal of Logistics Management, 14(1), 1-17. http:// dx.doi.org/10.1108/09574090310806503.

Montabon, F., Sroufe, R., \& Narasimhan, R. (2007). An examination of corporate reporting, environmental management practices and firm performance. Journal of Operations Management, 25(5), 998-1014. http:// dx.doi.org/10.1016/j.jom.2006.10.003.

Morali, O., \& Searcy, C. (2013). Review of Sustainable Supply Chain Management Practices in Canada. Journal of Business Ethics, 117(3), 635-658. http://dx.doi. org/10.1007/s10551-012-1539-4.

Niemelä-Nyrhinen, F., \& Uusitalo, O. (2013). Identifying potential sources of value in a packaging value chain. 
Journal of Business and Industrial Marketing, 28(2), 76-85. http://dx.doi.org/10.1108/08858621311295227.

Nilsson, F., Fagerlund, M., \& Körner, J. (2013). Globally standardized versus locally adapted packaging: a case study at Sony Ericsson Mobile Communications AB. International Journal of Retail \& Distribution Management, 41(5), 396-414. http://dx.doi.org/10.1108/ IJRDM-05-2013-0091.

Nordstrand, T. (2004). Analysis and testing of corrugated board panels into the post-buckling regime. Composite Structures, 63(2), 189-199. http://dx.doi.org/10.1016/ S0263-8223(03)00155-7.

Parikh, P., \& Meller, R. (2008). Selecting between batch and zone order picking strategies in a distribution center. Transportation Research Part E, Logistics and Transportation Review, 44(5), 696-719. http://dx.doi. org/10.1016/j.tre.2007.03.002.

Pelegrini, A. V. (2005). O processo de modularização em embalagens orientado para a customização em massa: uma contribuição para a gestão do design (Dissertação de mestrado). Programa de Pós-Graduação em Engenharia Mecânica, Universidade Federal do Paraná, Curitiba.

Pohl, L., Meller, R., \& Gue, K. (2011). Turnover-based storage in non-traditional unit-load warehouse designs. IIE Transactions, 43(10), 703-720. http://dx.doi.org/1 0.1080/0740817X.2010.549098.

Qi, C., \& Chang, N. (2013). Integrated carbon footprint and cost evaluation of a drinking water infrastruture system for screening expansion alternatives. Journal of Cleaner Production, 60(1), 170-181. http://dx.doi. org/10.1016/j.jclepro.2012.10.032.

Ramseur, J. (2008). The role of offsets in a greenhouse gas emissions cap and trade program: potential benefits and concerns (pp. 5-8, CRS Repor for Congress). Washington: Congressional Research Service.

Rao, P. (2007). Greening of the supply chain: an empirical study for SMES in the Philippine context. Journal of Asia Business Studies, 1(2), 55-66. http://dx.doi. org/10.1108/15587890780001296.

Rouwenhorst, B., Reuter, B., Stockrahm, V., Van Houtum, G., Mantel, J., \& Zijm, M. (2000). Warehouse design and control: framework and literature review. European Journal of Operational Research, 122(3), 515-533. http://dx.doi.org/10.1016/S0377-2217(99)00020-X.

Rundh, B. (2009). Packaging design: creating competitive advantage with product packaging. British Food Journal, 111(9), 988-1002. http://dx.doi. org/10.1108/00070700910992880.

Sharfman, M., Ellington, T., \& Meo, M. (1997). The next step in becoming "green": life cycle oriented environmental management. Business Horizons, 40(3), 13-22. http:// dx.doi.org/10.1016/S0007-6813(97)90048-3.

Shiau, J.-Y., \& Lee, M.-C. (2010). A warehouse management system with sequential picking for multi-container deliveries. Computers \& Industrial Engineering, 58(3), 382-392. http://dx.doi.org/10.1016/j.cie.2009.04.017.

Silva, D., Renó, G., Sevegnani, G., Sevegnani, T., \& Truzzi, O. (2013). Comparison of disposable and returnable packaging: a case study of reverse logistics in Brazil. Journal of Cleaner Production, 47(1), 377-387. http:// dx.doi.org/10.1016/j.jclepro.2012.07.057.

Van Nieuwenhuyse, I., \& Koster, R. (2009). Evaluating order throughput time in 2-block warehouses with time window batching. International Journal of Production Economics, 121(2), 654-664. http://dx.doi.org/10.1016/j. ijpe.2009.01.013.

Van Sluisveld, M., \& Worrell, E. (2013). The paradox of packaging optimization: a characterization of packaging source reduction in the Netherlands Resources. Conservation and Recycling, 73(1), 133-142. http:// dx.doi.org/10.1016/j.resconrec.2013.01.016.

Veludo, M. (2004). A gestão e a organização material dos stocks: introdução ao aprovisionamento e gestão de stocks (pp. 31-54). Lisboa: Instituto do Emprego e Formação Profissional de Lisboa.

Verghese, K., \& Lewis, H. (2007). Environmental innovation in industrial packaging: a supply chain approach. International. Journal of Production Research, 45(18-19), 4381-4401. http://dx.doi.org/10.1080/00207540701450211.

Williams, H., Wikström, F., \& Löfgren, M. (2008). A life cycle perspective on environmental effects of customer focused packaging development. Journal of Cleaner Production, 16(7), 853-859. http://dx.doi.org/10.1016/j. jclepro.2007.05.006.

Woodside, A., \& Wilson, E. (2003). Case study research methods for theory building. Journal of Business and Industrial Marketing, 18(6-7), 493-508. http://dx.doi. org/10.1108/08858620310492374.

Xavier, L., \& Corrêa, H. (2013). Sistemas de logística reversa: criando cadeias de suprimentos sustentáveis. São Paulo: Atlas.

Yang, C., Lin, S., Chan, Y., \& Sheu, C. (2010). Mediated effect of environmental management on manufacturing competitiveness: an empirical study. International Journal of Production Economics, 123(1), 210-220. http://dx.doi.org/10.1016/j.ijpe.2009.08.017.

Yang, M., Hong, P., \& Modi, S. (2011). Impact of lean manufacturing and environmental management on business performance: An empirical study of manufacturing firms. International Journal of Production Economics, 129(2), 251-261. http://dx.doi.org/10.1016/j.ijpe.2010.10.017.

Yin, R. (2010). Estudo de caso: planejamento e métodos (4. ed.). Porto Alegre: The Bookman.

Zhang, G., \& Zhao, Z. (2012). Green packaging management of logistics enterprises. Physics Procedia, 24, 900-905. http://dx.doi.org/10.1016/j.phpro.2012.02.135. 